\title{
Chemical Non-Innocence of an aliphatic PNP Pincer Ligand
}

\author{
Felix Schneck, ${ }^{[a]}$ Markus Finger, ${ }^{[a]}$ Moniek Tromp ${ }^{[b]}$ and Sven Schneider ${ }^{*[a]}$
}

The synthesis of the divinylamido PNP nickel(II) complex [NiBr$\left.\left\{\mathrm{N}(\mathrm{CHCHPtBu})_{2}\right\}\right]$ is reported. This compound exhibits reversible, ligand centered oxidation and protonation reactions. The resulting pincer chemical non-innocence can be utilized for benzylic $\mathrm{C}-\mathrm{H}$ hydrogen atom abstraction. The thermochemistry and kinetics of hydrogen atom transfer were examined.

Tridentate, monoanionic 'pincer-type' ligands are extensively used in small molecule activation and homogeneous catalysis. ${ }^{[1]}$ Their popularity is related to the modular steric and electronic properties. Cooperating and redox non-innocent pincer ligands (Scheme 1, $A$ and $B$ ) can serve as reversible reservoirs for protons and electrons, respectively, and their use facilitated the remarkable advances in base metal catalysis. ${ }^{[2,3]}$ The simultaneous accessibility of both redox and proton cooperativity enables concerted proton-electron transfer (CPET), which can be considered as ligand chemical non-innocence (Scheme $1, C$ ).$^{[4]}$ Such pathways are relevant for ligand centered activation of substrates with unfavorable redox potentials and $\mathrm{p} K_{\mathrm{a}}$, such as weakly activated hydrocarbons. ${ }^{[5]}$

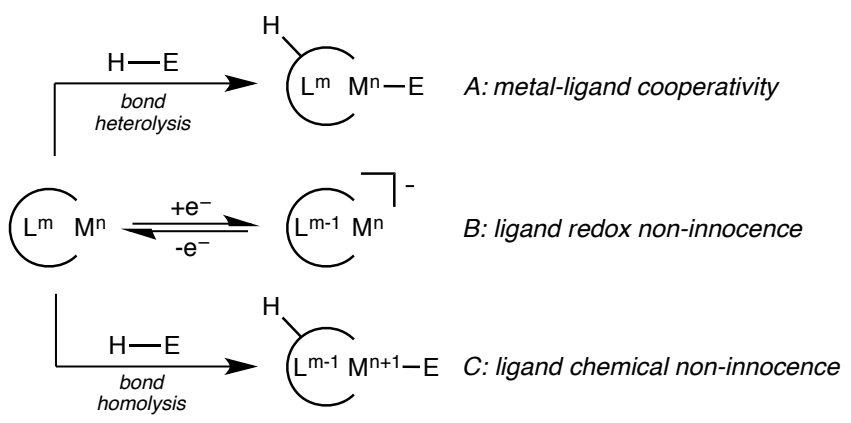

Scheme 1. Different modes of metal-ligand cooperative reactivity.

Systematic examinations of such chemically non-innocent ${ }^{[6]}$ pincer ligands are rare. Mindiola and co-workers demonstrated ligand redox non-innocence for the nickel pincer complex $\left[\mathrm{NiCl}\left\{\mathrm{N}\left(2-\mathrm{C}_{6} \mathrm{H}_{3}-5-\mathrm{CH}_{3}-\mathrm{PiPr}_{2}\right)_{2}\right\}\right]^{+}{ }^{[7]}$ But the absence of a basic ligand site prevents ligand centered hydrogen atom transfer (HAT) reactivity. The groups of Milstein and Chirik independently reported HAT from the methylene groups of $\left[\mathrm{CoX}\left\{\mathrm{NC}_{5} \mathrm{H}_{3}\left(\mathrm{CH}_{2} \mathrm{PR}_{2}\right)_{2}\right\}\right]\left(\mathrm{X}=\mathrm{H}, \mathrm{CH}_{3} ; \mathrm{R}=i \mathrm{Pr}, t \mathrm{Bu}\right) .^{[8,9]}$ The bond dissociation free energies (BDFEs) of the $\mathrm{CH}_{2}$ groups were computed to be around $40-50 \mathrm{kcal} / \mathrm{mol}$, suggesting they are not suitable for HAT form substrate $\mathrm{C}-\mathrm{H}$ bonds. ${ }^{[4 a]}$ We here present an aliphatic analogue of Mindiola's complex which exhibits pincer centered proton cooperativity, redox non-innocence and chemical non-innocence enabling benzylic C-H HAT reactivity of the pincer.

Dialkylamido complex $\left[\mathrm{NiBr}\left\{\mathrm{N}\left(\mathrm{CH}_{2} \mathrm{CH}_{2} \mathrm{PtBu}\right)_{2}\right\}\right]$ (1, Scheme 2) was isolated in over $80 \%$ yield upon reaction of $\left[\mathrm{NiBr}_{2}(\mathrm{dme})\right]$ (dme = dimethoxyethane) with $\mathrm{HN}\left(\mathrm{CH}_{2} \mathrm{CH}_{2} \mathrm{PtBu}\right)_{2}$ and $\mathrm{KOtBu}$. Spectroscopic characterization and single-crystal X-ray diffraction of 1 (Electronic Supporting Information, ESI) confirm square-planar coordination of the nickel ion in solution and in the solid-state. The examination of 1 by cyclic voltammetry (CV) reveals irreversible oxidation at $E_{\mathrm{pa}}=0.00 \mathrm{~V}\left(\mathrm{vs}\right.$. $\left.\mathrm{FeCp}_{2} / \mathrm{FeCp}_{2}{ }^{+}\right)$, which becomes quasi-reversible at high scan-rates, followed by reversible oxidation at $E_{1 / 2}=0.29 \mathrm{~V}$ (see ESI). The scan-rate dependence of the peak currents indicates an ECE-mechanism. These observations are reminiscent of the related iridium(I) amido complexes $\left[\operatorname{lrL}\left\{\mathrm{N}_{(}\left(\mathrm{CH}_{2} \mathrm{CH}_{2} t \mathrm{Bu}_{2}\right)_{2}\right\}\right](\mathrm{L}=\mathrm{CO}, \mathrm{PMe}$, cyclooctene), which disproportionate into the amine and imine derivatives, respectively, upon one-electron oxidation. ${ }^{[10]}$

To enhance the oxidative stability of the pincer ligand framework, the backbone was dehydrogenated with hydrogen acceptor 2,4,6-tert-butylphenoxy radical (TBP). We recently utilized this template ligand synthesis to isolate the divinylamide complex $\left[\mathrm{CoCl}\left\{\mathrm{N}\left(\mathrm{CHCHPtBu}_{2}\right)_{2}\right\}\right]^{+}$as a rare example for a square-planar cobalt(III) complex. ${ }^{[11]}$ The reaction

[a] Institut für Anorganische Chemie, Georg-August-Universität, Tammannstr. 1, 37077 Göttingen, Germany

[b] University of Amsterdam, Van t Hoff Institute for Molecular Sciences, Sustainable Chemistry, Science Park 904, 1098 XH Amsterdam, The Netherlands

Supporting information for this article is given via a link at the end of the document. 
of 1 with 4.5 equiv. TBP results in clean formation of nickel(II) divinylamido complex $\left[\mathrm{NiBr}\left\{\mathrm{N}(\mathrm{CHCHPtBu})_{2}\right\}\right](2)$ in over $90 \%$ isolated yield (Scheme 2). Spectroscopic and crystallographic characterization (Figure 2 and ESI) confirms ligand dehydrogenation (N1-C1 1.3718(16) A; C1-C2 1.349(2) Å).

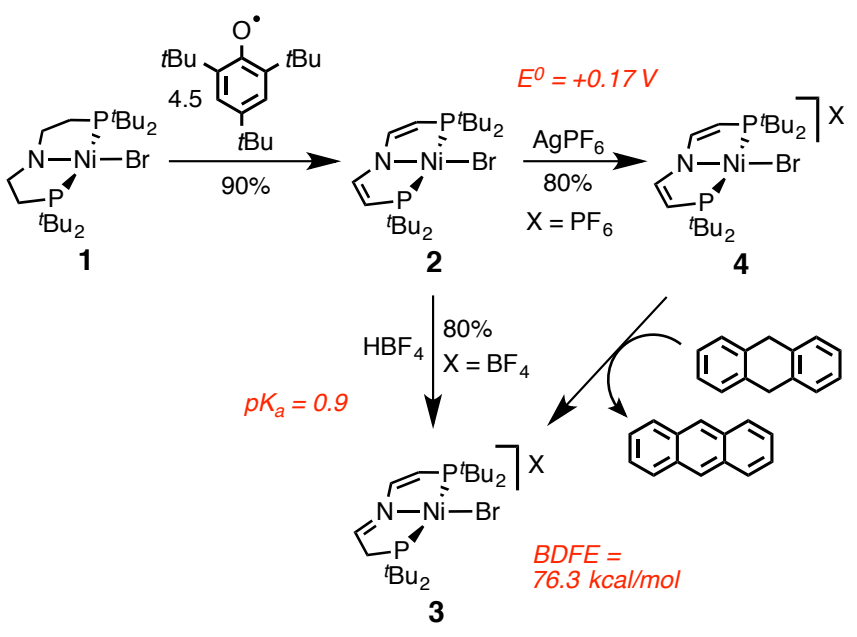

Scheme 2. Synthesis and reactivity of nickel PNP pincer complexes 2-4 and thermochemical relations derived in DMSO.

Oxidation and protonation of 2 were examined independently to estimate the viability for HAT reactivity with the Ni(PNP) platform. Our group previously demonstrated that related vinyl- and divinylamido pincer ligands offer $C$-basic sites. ${ }^{[11,12]}$ Accordingly, reaction of 2 with strong acids like $\mathrm{HBF}_{4} \cdot \mathrm{OEt}_{2}$ affords vinyl imine complex $\left[\mathrm{NiBr}\left\{\mathrm{N}\left(\mathrm{CHCH}_{2} \mathrm{PtBu} \mathrm{Bu}_{2}\right)\left(\mathrm{CHCHPtBu}_{2}\right)\right\}\right] \mathrm{BF}_{4}\left(3^{\mathrm{BF} 4}\right)$ in over $80 \%$ isolated yield (Scheme 2). Ligand asymmetrization results in two signals in the ${ }^{31} \mathrm{P}\left\{{ }^{1} \mathrm{H}\right\}$ NMR spectrum with mutual trans-coupling $\left({ }^{2} J_{\mathrm{PP}}=294 \mathrm{~Hz}\right)$. Protonation in vinylic position is confirmed by single crystal X-ray diffraction of 3 (Figure 1), resulting in lengthening of the C11-C12 bond (1.434(3) $\AA$ ) and shortening of the $\mathrm{N} 1-\mathrm{C} 11$ imine double bond $(1.322(2) \AA)$ with respect to parent 2 . The methylene $\mathrm{C}-\mathrm{H} p \mathrm{~K}_{\mathrm{a}}(=0.91)$ of 3 was derived by ${ }^{31} \mathrm{P}\left\{{ }^{1} \mathrm{H}\right\}$ NMR titration of 2 with HOTf in $\mathrm{d}_{6}$-dmso (see ESI). Minor amounts of an unidentified side product at $\delta\left({ }^{31} \mathrm{P}\right)=58.1 \mathrm{ppm}$ were also detected in the equilibrium mixture.
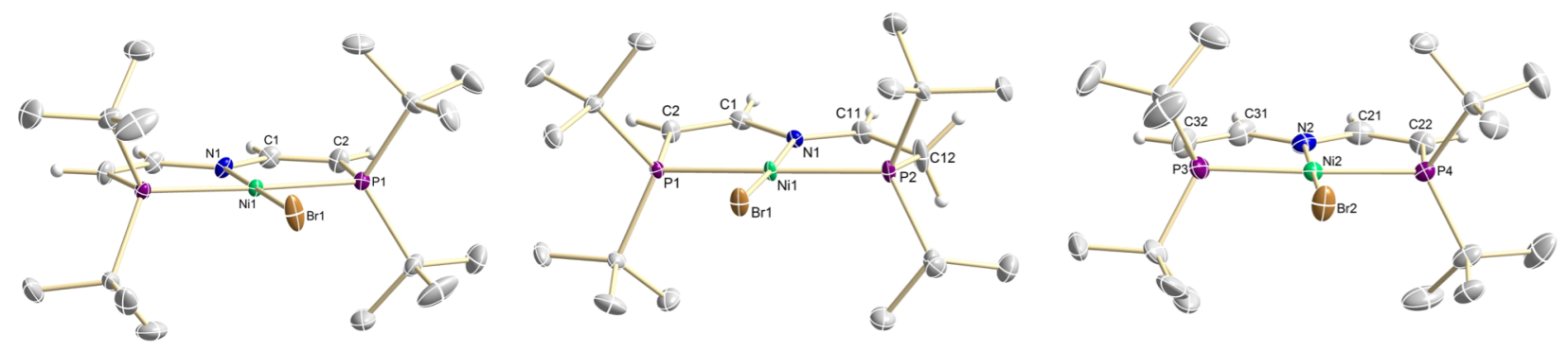

Figure 1. Molecular structures of 2 (left), 3 (center, OTf anion omitted), and $\mathbf{4}$ (right, $\mathrm{PF}_{6}^{-}$anion omitted) in the crystal with thermal ellipsoids drawn at the $50 \%$ probability level. Hydrogen atoms are omitted for clarity. Selected bond lengths $(\AA)$ and angles (deg) of 2: Ni1-Br1 2.3094(3), Ni1-P1 2.2368(4), Ni1-N1 1.8814(15), N1-C1 1.3718(16), C1-C2 1.349(2); P1-Ni1-N1 83.321(10), N1-Ni1-Br1 180.0, P1-Ni1-P1' 170.64(2). 3: Ni1Br1 2.2985(3), Ni1-P1 2.2216(5), Ni1-P2 2.2295(6), Ni1-N1 1.9034(16), N1-C1 1.395(2), N1-C11 1.322(2), C1-C2 1.352(3), C11-C12 1.434(3); $\mathrm{P} 1-\mathrm{Ni1}-\mathrm{N} 1$ 86.31(5), P2-Ni1-N1 85.79(5), N1-Ni1-Br1 176.25(5), P1-Ni1-P2 171.78(2). 4: Ni1-Br1 2.3031(4), Ni1-P1 2.2429(7), Ni1-P2 2.2408(7), Ni1-N1 1.878(2), N1-C1 1.366(3), N1-C11 1.370(3), C1-C2 1.354(4), C11-C12 1.361(4); P1-Ni1-N1 85.73(7), P2-Ni1-N1 86.02(7), $\mathrm{N} 1-\mathrm{Ni1}-\mathrm{Br} 1$ 179.64(6), P1-Ni1-P2 171.47(3).

However, this signal exhibits no cross peaks with 2 and 3 in a ${ }^{31} \mathrm{P}_{-}{ }^{31} \mathrm{P}$ EXSY spectrum suggesting a negligible effect on the equilibrium constant. In contrast to 1 , the $\mathrm{CV}$ of 2 features reversible oxidation at $E_{1 / 2}=+0.19 \mathrm{~V}$ in $\mathrm{THF}(0.17 \mathrm{~V}$ in dmso) confirming the enhanced oxidative stability of the divinylamido ligand. 


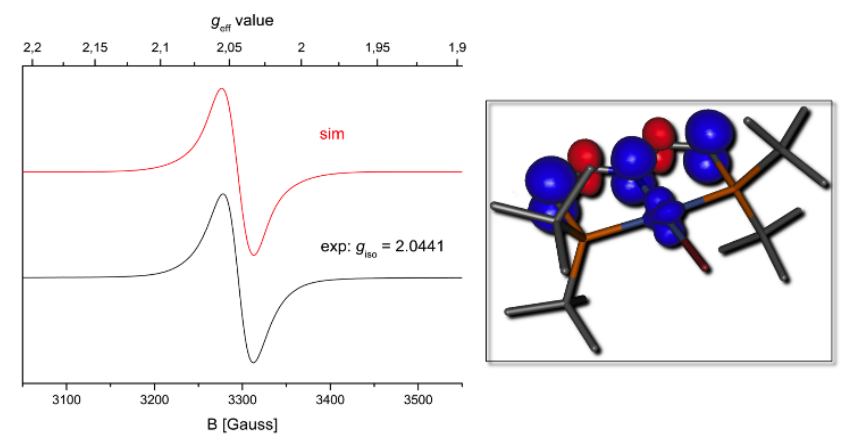

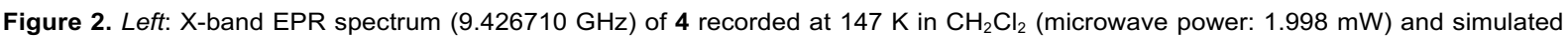
spectrum in red $\left(\mathrm{g}_{\mathrm{iso}}=2.044, \mathrm{w}_{\mathrm{x}}=\mathrm{w}_{\mathrm{y}}=1.7 \mathrm{mT}, \mathrm{w}_{\mathrm{z}}=63 \mathrm{mT}\right)$. Right: Computed spin density of 4.

Chemical oxidation of 2 with $\mathrm{AgPF}_{6}$ in chlorobenzene allows gives the radical complex $\left[\mathrm{NiBr}\left\{\mathrm{N}\left(\mathrm{CHCHPtBu}_{2}\right)_{2}\right\}\right] \mathrm{PF}_{6}(\mathbf{4})$ in isolated yield around $80 \%$ (Scheme 2). The molecular structure of $\mathbf{4}$ in the crystal is very close to that of parent 2 (Figure 1). Notably, the nickel-to-ligand bond distances are almost invariant within error suggesting that oxidation is not purely metal centred. The magnetic moment of 4 in solution at room temperature derived by Evans' method $\left(\mu=1.9 \mu_{\mathrm{B}}\right)$ is in agreement with an $S=1 / 2$ ground state. Hence, no signal was found by ${ }^{31} \mathrm{P} N M R$ spectroscopy and paramagnetically shifted and broadened signals in the ${ }^{1} \mathrm{H}$ NMR spectrum, respectively. The EPR spectrum of 4 in $\mathrm{CH}_{2} \mathrm{Cl}_{2}$ both at r.t. and in frozen solution $(147 \mathrm{~K}$ ) as well as in the solid state show a broad isotropic signal at $g=2.044$ (Figure $2)$. Hyperfine interaction is not resolved. The $g$-value is close to that of the free electron $\left(g_{\mathrm{e}}=2.0023\right)$ suggesting spin delocalization onto the pincer ligand. The absorption spectrum in benzene exhibits intense bands at $485 \mathrm{~nm}\left(\varepsilon=2.510^{3}\right.$ $\mathrm{M}^{-1} \mathrm{~cm}^{-1}$ with a shoulder at $\left.506 \mathrm{~nm}\right)$ and $547 \mathrm{~nm}\left(\varepsilon=1.510^{3} \mathrm{M}^{-1} \mathrm{~cm}^{-1}\right)$ in the visible region and a broad NIR band at 1070 $\mathrm{nm}\left(\varepsilon=830 \mathrm{M}^{-1} \mathrm{~cm}^{-1}\right)$. The solvatochromic shift using dmso as solvent $\left(\Delta \lambda=-80 \mathrm{~nm}, \varepsilon=98010^{3} \mathrm{M}^{-1} \mathrm{~cm}^{-1}\right)$ indicates charge-transfer character of the NIR band. While parent 2 also exhibits a broad absorption at $483 \mathrm{~nm}\left(\varepsilon=895 \mathrm{M}^{-1} \mathrm{~cm}^{-1}\right)$, NIR features are absent. Such bands can be indicative of ligand redox non-innocence, typically originating from low energy $\pi-\pi^{*}$ or LLCT transitions, which are spin- and dipole-allowed. ${ }^{[13]}$ For comparison, Mindiola's $\left[\mathrm{NiCl}\left\{\mathrm{N}\left(2-\mathrm{C}_{6} \mathrm{H}_{3}-5-\right.\right.\right.$ $\left.\left.\left.\mathrm{CH}_{3}-\mathrm{PiPr}_{2}\right)_{2}\right\}\right]^{+}$exhibits an NIR absorption at $872 \mathrm{~nm}\left(\varepsilon=1359 \mathrm{M}^{-1} \mathrm{~cm}^{-1}\right) \cdot{ }^{[7]}$

The ligand non-innocence is corroborated by Ni K-edge X-ray absorption spectroscopy (XAS). All three complexes 2-4 exhibit a very similar X-ray absorption near edge structure (XANES) as well as extended X-ray absorption fine structure (EXAFS, see ESI). The XANES edge position is very dependent on the charge distribution in the system as a result from the ligand environment and geometry, ${ }^{[14]}$ indicating that the local $\mathrm{Ni}$ electronic and structural properties are almost invariant for 2-4. The very small changes in whiteline shape reflect minor differences in bond lengths and geometry. Furthermore, the distinct feature in the rising edge at $8336 \mathrm{keV}$ for all three compounds, which can in square-planar transition metal complexes directly be attributed to the $1 \mathrm{~s}-\mathrm{to}-4 \mathrm{p}_{\mathrm{z}}$ transition (confirmed for $\mathbf{2 - 4}$ by XANES simulations; see ESI Figure S16), ${ }^{[15,16,17]}$ supports low spin nickel(II) for all three complexes.

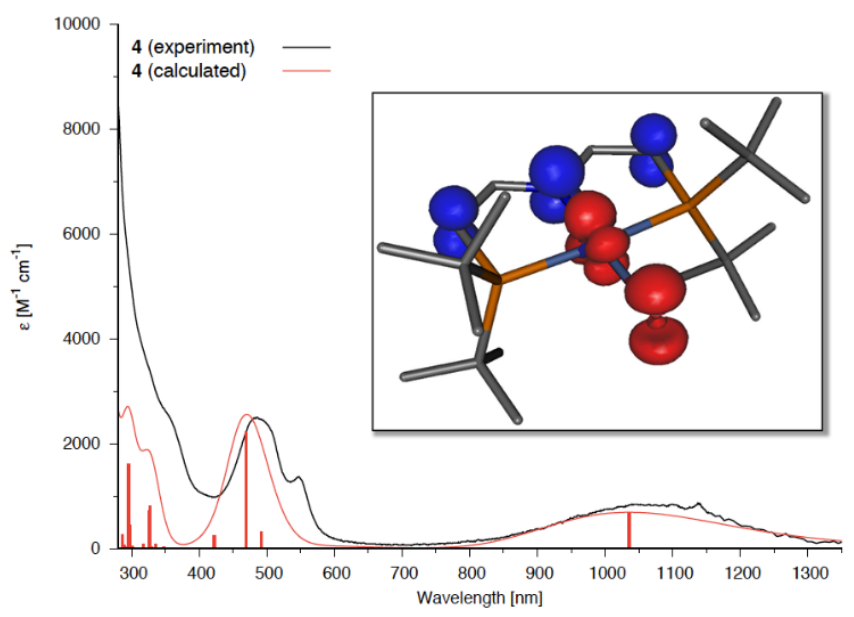

Figure 3. Experimental and computed UV/Vis/NIR spectra of 4 in benzene. Insert: Calculated difference density of the transition at 1036 $\mathrm{nm}$; blue: positive density; red: negative density). 
This interpretation is further backed by DFT computations (see ESI for details). The HOMO of 2 exhibits major contributions from the $\mathrm{N}$ and $\mathrm{C} 3 p$ orbitals in the pincer ligand backbone and a minor, antibonding participation of the nickel $d_{x z}$ orbital. Upon oxidation the main portion of the atomic spin density of 4 (Figure 2) is found within the $\pi$-system of the divinylamido moiety, and only $20 \%$ within the atomic basin of the metal. A slightly rhombic $g$-tensor was computed with very small g-factor anisotropy $(\Delta g=0.042)$. While the computed $g_{\text {iso }}(2.031)$ is in good agreement with experiment the anisotropy seems to be slightly overestimated computationally. The experimental UV/Vis/NIR-spectrum was nicely reproduced by TD-DFT computations (Figure 3). The density difference plot of the low-energy transition at $1036 \mathrm{~nm}$ reflects both $\mathrm{Ni} \rightarrow$ PNP MLCT and $\mathrm{Br} \rightarrow$ PNP LLCT character. Its main contribution arises from electron transfer from a mainly metal $d$ - and bromine $p$-orbital based spin-orbital to the SOMO (see ESI). The computed solvatochromic shift for this band $(\Delta \lambda=-81 \mathrm{~nm})$ is in excellent agreement with experiment.

The driving force of CPET reactions can be estimated from the quantification of redox and protonation equilibria via thermochemical cycles. ${ }^{[18]}$ For example, the bond dissociation free energy of the methylene $\mathrm{C}-\mathrm{H}$ bonds of $\mathbf{3}$ in dmso can be derived from the electrochemical potential of the $2 / 3$ redox couple $\left(E^{0}=+0.17 \mathrm{~V}\right)$ and the $\mathrm{p} K_{\mathrm{a}}$ value of $3(+0.9)$. The resulting value $\left(\mathrm{BDFE}_{\mathrm{exp}}=76.3 \mathrm{kcal} / \mathrm{mol}\right)$ is in excellent agreement with our computational estimate $\left(\mathrm{BDFE} \mathrm{E}_{\mathrm{DFT}}=77.2\right.$ $\mathrm{kcal} / \mathrm{mol})$. This $\mathrm{C}-\mathrm{H}$ BDFE suggests, that the radical complex 4 should be competent to homolytically cleave activated $\mathrm{C}-\mathrm{H}$ bonds, as in benzylic hydrocarbons. This was tested with 9,10-dihydroanthracene (DHA). The C-H BDFE of DHA is close $\left(\mathrm{BDFE}_{\mathrm{C}-\mathrm{H}}=75.0 \mathrm{kcal} / \mathrm{mol}\right.$ in dmso) and proton or electron transfer from DHA to 4 are thermodynamically not accessible. ${ }^{[19]}$ Accordingly, DHA reacts with 4 in chlorobenzene at room temperature over the course of some minutes (Scheme 1). Besides 3 and anthracene no other side-products or intermediates were observed by NMR spectroscopy. Notably, oxidation of benzylic hydrocarbons like DHA with metal-oxo oxidants often gives mixtures of dehydrogenation and oxygenation products. ${ }^{[20]}$

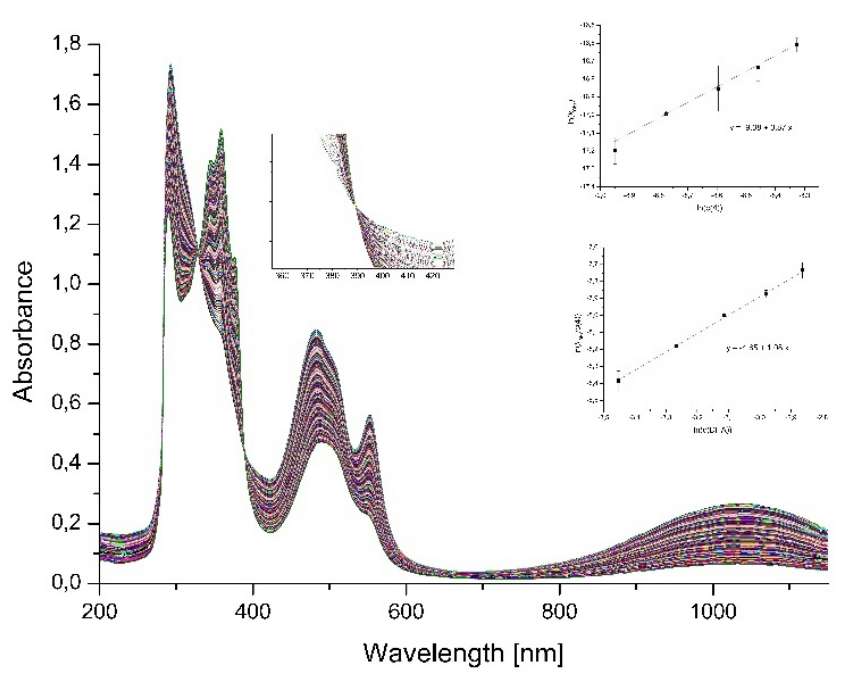

Figure 4. HAT from DHA to 4 in chlorobenzene at $25^{\circ} \mathrm{C}$ followed by UV/Vis/NIR spectroscopy. Left insert: Isosbestic point at $389 \mathrm{~nm}$. Right insert: plot of first-order rate constant $\ln \left(k_{\mathrm{obs}}\right)$ vs. $\ln [4]$.

The kinetics of this reaction were examined spectrophotometrically, following the decay of the NIR band of 4 under pseudo first-order conditions (Figure 4 and ESI). Isosbestic points in the UV/Vis region at 328 and $389 \mathrm{~nm}$ suggest that no long-lived intermediates build up in considerable amounts. The kinetic data can be fit to a simple rate law, i.e. firstorder in 4 and DHA $\left(r=-\mathrm{d}[\mathbf{4}] / \mathrm{d} t=2 k_{\exp } \cdot[4] \cdot[\mathrm{DHA}]\right)$, respectively, with a second-order rate constant $k_{\exp }=$ $3.9 \cdot 10^{-3} \pm 2 \cdot 10^{-4} \mathrm{M}^{-1} \mathrm{~s}^{-1}$. This value can be compared with an estimate from applying the Marcus cross-relation: ${ }^{[21]}$

$$
k_{H A T}=\sqrt{k_{3 / 4} k_{D H A / H A} K_{H A T} f}
$$

This equation connects the HAT cross rate constant $\left(k_{H A T}\right)$ to the two degenerate self-exchange rate constants $\left(k_{3 / 4}\right.$ and $\left.k_{D H A / H A}\right)$ and the overall driving force $\left(K_{H A T}\right)$. Meyer and co-workers found for a large range of transition metal oxidants an agreement within one to two orders of magnitude. ${ }^{[5]}$ The $\mathbf{3 / 4}$ self exchange rate was derived by ${ }^{1} \mathrm{H}$ NMR line 
broadening in $\mathrm{d}_{5}-\mathrm{PhCl}\left(k_{3 / 4}=\left(\pi \Delta \mathrm{W}_{3}\right) /[4]=2.2 \cdot 10^{3} \mathrm{M}^{-1} \mathrm{~s}^{-1}\right)$, ${ }^{[22]}$ showing unusually rapid $\mathrm{C}-\mathrm{H}$ self exchange, comparable to $\mathrm{N}-\mathrm{H} / \mathrm{O}-\mathrm{H}$ self exchange rates. With the self-exchange rate constant that was reported for DHA/HA $\left(k_{\mathrm{DAH} / \mathrm{HA}}=5 \cdot 10^{-11} \mathrm{M}^{-}\right.$ $\left.{ }^{1} \mathrm{~s}^{-1}\right),{ }^{[23]}$ the driving force for cross HAT $\left(K_{\mathrm{HAT}}=2.1 \cdot 10^{-2}\right)$ and $f$ close to unity for a reaction with small driving force, $k_{\mathrm{HAT}}=$ $4.7 \cdot 10^{-5} \mathrm{M}^{-1} \mathrm{~s}^{-1}$ is obtained. ${ }^{[24]}$ Hence, without statistical correction for the number of $\mathrm{H}$-donor and -acceptor sites, this estimate lies within two orders of magnitude of the experimental value. Some deviation can be attributed to the different solvents that had to be used for derivation of $K_{\text {HAT }}(\mathrm{dmso})$ vs. $k_{3 / 4}$ and $k_{\exp }(\mathrm{PhCl})$, respectively, due to the limited stability of 4 in dmso. ${ }^{[25]}$

In conclusion, we presented the synthesis of nickel complexes with an unsaturated, aliphatic divinylamido PNP pincer ligand. Predominantly ligand centred one electron oxidation of nickel(II) complex 2 is supported by EPR, UV/Vis/NIR and XAS spectroscopy in combination with DFT computations. While pincer redox non-innocence was previously reported for a related aromatic diarylamido PNP nickel complex, ${ }^{[7]} 4$ also exhibits facile ligand chemical non-innocence of the pincer backbone. The driving force for HAT was estimated via a thermochemical cycle suggesting the accessibility of benzylic $\mathrm{C}-\mathrm{H}$ bond activation. This was exemplified by the stoichiometric oxidation of DHA to anthracene and 3. The rate constant is in decent agreement with an estimate based on the Markus cross relation further supporting an HAT mechanism. These results emphasize the versatility of functional pincer ligands as building blocks in bond activation and catalysis.

\section{Acknowledgements}

This work was supported by the ERC (Grant Agreement 646747, Consolidator Grant to S.S.) and NWO (NWO-VIDI to M.T.). We acknowledge the Dutch-Belgian Beamline at the European Synchrotron Radiation Facility for beamtime under project 26-01-1080 and Bas Venderbosch, Lukas Wolzak and Jean Pierre Oudsen for measuring the XAS data.

Keywords: nickel $\bullet$ pincer ligand $\cdot$ non-innocent ligand $\cdot \mathrm{C}-\mathrm{H}$ activation $\bullet$ hydrogen atom transfer

[1] (a) Organometallic Pincer Chemistry (Eds.: G. van Koten, D. Milstein) Springer, 2013. (b) Pincer and Pincer-Type Complexes: Applications in Organic Synthesis and Catalysis (Eds.: K. J. Szabo, O. F. Wendt), Wiley-VCH, 2014.

[2] (a) H. Grützmacher, Angew. Chem. Int. Ed. 2008, 47, 1814. (b) J. I. van der Vlugt, 2012, 363. (c) B. Askevold, H. W. Roesky, S. Schneider, Chem CatChem 2012, 4, 307. (d) J. R. Khusnutdinova, D. Milstein, Angew. Chem. Int. Ed. 2015, 54, 12236.

[3] (a) V. Lyaskovskyy, B. de Bruin, ACS Catalysis 2012, 2, 270. (b) O. R. Luca, R. H. Crabtree, Chem. Soc. Rev. 2013, 42, 1440. (c) P. J. Chirik, Acc. Chem. Res. 2015, 48, 1687.

[4] (a) J. J. Warren, T. A. Tronic, J. M. Mayer, Chem. Rev. 2010, 110, 6961. (b) D. R. Weinberg, C. J. Gagliardi, J. F. Hull, C. F. Murphy, C. A. Kent, B. C. Westlake, A. Paul, D. H. Ess, D. G. McCafferty, T. J. Meyer, Chem. Rev. 2012, 112, 4016.

[5] J. M. Mayer, Acc. Chem. Res. 2011, 44, 36.

[6] The term chemical non-innocence is used throughout this paper for ligand centered PCET to distinguish it from pure redox non-innocence (ET) and ligand cooperativity (PT), respectively.

[7] D. Adhikari, S. Mossin, F. Basuli, J. C. Huffman, R. K. Szilagyi, K. Meyer, D. J. Mindiola, J. Am. Chem. Soc. 2008, $130,3676$.

[8] E. Khaskin, Y. Diskin-Posner, L. Weiner, G. Leitus, D. Milstein, Chem Commun. 2013, 49, 2771.

[9] S. P. Semproni, C. Milsmann, P. J. Chirik, J. Am. Chem. Soc. 2014, 136, 9211.

[10] B. Askevold, A. Friedrich, M. R. Buchner, B. Lewall, A. C. Filippou, E. Herdtweck, S. Schneider, J. Organomet. Chem. 2013, 744, 35.

[11] P. O. Lagaditis, B. Schluschaß, S. Demeshko, C. Würtele, S. Schneider, Inorg. Chem. 2016, 55, 4529.

[12] A. Friedrich, M. Drees, M. Käss, E. Herdtweck, S. Schneider, Inorg. Chem. 2010, 49, 5482.

[13] K. Ray, T. Petrenko, K. Wieghardt, F. Neese, Dalton Trans. 2007, 1552.

[14] M. Tromp, J. O. Moulin, G. Reid, J. E. Evans, AIP 2007, CP882, 699

[15] T. A. Smith, J. E. Penner-Hahn, M. A. Berding, S. Doniach, K. O. Hodgson, J. Am. Chem. Soc. 1985, 107, 5945.

[16] L. X. Chen, W. J. H. Jäger, G. Jennings, D. J. Gosztola, A. Munkholm, J. P. Hessler, Science 2001, 292, 262.

[17] G. J. Colpas, M. J. Maroney, C. Bagyinka, M. Kumar, W. S. Willis, S. L. Suib, N. Baida, P. K. Mascharak, Inorg. Chem. 1991, $30,910$.

[18] F. G. Bordwell, X.-M. Zhang, Acc. Chem. Res. 1993, 26, 510. (b) V. D. Parker, K. L. Handoo, F. Roness, M. Tilset, J. Am. Chem. Soc. $1991,113,7493$.

[19] The $p K_{\mathrm{a}}$ of DHA $(=30.1)^{[4 \mathrm{a}]}$ in DMSO is about 30 orders of magnitude higher than that of $\mathbf{3}$ and $\mathbf{4}$ is expected to be even less basic than 2. $E\left(D H A^{+/ 0}\right)$ can be estimated from this value and the reported BDFE indicating that electron transfer is also not accessible.

[20] J. R. Bryant, J. M. Mayer, J. Am. Chem. Soc. 2003, 125, 10325 and references cited therein.

[21] J. P. Roth, J. C. Yoder, T.-J. Won, J. M. Mayer, Science 2001, 294, 2524.

[22] J. C. Yoder, J. P. Roth, E. M. Gussenhoven, A. S. Larsen, J. M. Mayer, J. Am. Chem. Soc. 2003, 125, 2629.

[23] J. J. Warren, J. M. Mayer, PNAS 2010, 107, 5282.

[24] R. A. Marcus, N. Sutin, Biochim. Biophys. Acta 1985, 811, 265.

[25] Major solvent effects for DAH/HA self-exchange are not expected but might be more pronounced for $3 / 4$ self-exchange due to the high acidity of 3 . $^{[23]}$ 